\title{
Acceptability for the Use of Postpartum Intrauterine Contraceptive Devices: Assiut Experience
}

\author{
Safwat A. Mohamed Momen A. Kamel Omar M. Shaaban \\ Hossam T. Salem \\ Department of Obstetrics and Gynecology, Faculty of Medicine, Assiut University, Assiut, Egypt
}

\section{Key Words}

Postpartum contraception - Postpartum intrauterine contraceptive device · Acceptability · Intrauterine contraceptive device

\begin{abstract}
Objectives: To evaluate the acceptance of postpartum intrauterine contraceptive devices (PPIUCD) among the inhabitants of Assiut governorate, Egypt and to study the factors that influence this acceptance. Subjects and Methods: Contraceptive counseling was given to 3,541 clients: 1,880 and 1,661 during the antenatal visits and postpartum hospitalization, respectively. Acceptors during antenatal counseling were to receive IUCDs via postplacental insertion in the case of vaginal delivery or transcesarean insertion in case of abdominal delivery. The clients who refused PPIUCD and chose interval IUCD insertion were referred to the Family Planning Clinic after the end of puerperium. Among postpartum counselees, PPIUCD acceptors received predischarge insertion within $48 \mathrm{~h}$ of delivery and the interval IUCD were referred to have IUCD inserted after the end of puerperium. The acceptance rate of both PPIUCD and interval IUCD and the percentage of actual insertions were recorded. The
\end{abstract}

causes of both acceptance and refusal were also recorded. Results: Of the 3,541 clients, 1,024 (28.9\%) accepted the use of IUCD after delivery. Acceptance was approximately the same during antenal and postpartum counseling: 26.4 and $31.8 \%$, respectively. Verbal acceptance was higher among women with formal education than among illiterate women. Planning another pregnancy in the near future, preference for another contraceptive method, namely lactational infertility, and complications from previous use of IUCD were the most common reasons for refusing the use of IUCD. Of the 1,024 verbal acceptors, only $243(23.7 \%)$ had the actual insertion of IUCD. Conclusion: Both the acceptance and actual insertion of IUCD were low probably because the use of IUCD is a new concept in the community. For these women, the only opportunity to receive information about contraceptives is during childbirth when they are in contact with medical personnel. Hence, it is suggested that family planning should be integrated with maternal and child-care services in order to effectively promote the use of contraceptive devices in these women who otherwise would not seek the use of such a device.

Copyright @ 2003 S. Karger AG, Basel

\section{KARGER \\ Fax + 41613061234 \\ E-Mail karger@karger.ch \\ www.karger.com

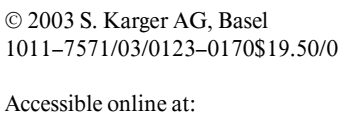

Prof. Hosam Thabet Salem

Department of Obstetrics and Gynecology, Faculty of Medicine

Assiut University

Assiut (Egypt)

Tel. +2088 335605, Fax +2088 333327, E-Mail hosamtsalem@yahoo.com 


\section{Introduction}

Contraceptive counseling has become an integral part of antenatal and postpartum programs as pregnant and postpartum women are generally highly motivated toward controlling their fertility either in spacing out their children or in stopping their fertility altogether. The time during pregnancy and that immediately after delivery may be the only time for the physician to connect with women who are poorly motivated to obtain routine health care, best described as 'crisis-oriented' [1]. The postpartum period is potentially an ideal time to begin contraception as women are more strongly motivated to do so at this time, which also has the advantage of being convenient for both patients and health-care providers [2].

The intrauterine contraceptive device (IUCD) is considered one of the most reliable, inexpensive, nonhormonal and reversible contraceptive methods suitable for a lactating mother [3] because it has no negative effects on lactation and may in fact increase its duration in some women and does not affect the quality of the breast milk $[3,4]$. Nowadays, postpartum IUCD (PPIUCD) has been established as an effective and reliable method of contraception as it offers numerous advantages: ease of insertion, minimal adverse impacts on breast-feeding, costeffectiveness, relief of overcrowded outpatient facilities and protection against unwanted pregnancy and consequent abortion [5]. In addition, insertion complaints caused by lochial blood and cramping are masked [6]. Hence we began the program of counseling women of Assiut governate, Egypt on the use of IUCD. In this paper we report our experience.

\section{Subjects and Methods}

Three thousand five hundred and forty-one pregnant women who attended the Obstetrics Service, Assiut University Hospital (AUH) were selected as subjects. After having approval from the ethics committee of the School of Medicine, Assiut University, informed consent was obtained from each participant in this study. Counseling on postpartum contraception was given either during antenatal care visits or during the postpartum stay in the hospital (and avoided during the intranatal period, when the women were in labor and therefore unable to make any informed decision). Participating staff and health workers received at least one course in counseling as well as prescribing and administering various contraceptives under the supervision of international visiting consultants from the Association of Voluntary Safe Contraception.

\section{Antenatal Counseling}

Counseling for postpartum family planning was given to 1,880 clients during final visits for antenatal care in AUH. During counsel- ing, postpartum contraception with IUCD was offered together with other options that included Norplant, progestogen-only injectables and minipills suitable for breast-feeders. The merits of each method, its common side effects and possible complications were explained to the clients. Each client was counseled individually, during which PPIUCD was introduced. This approach was used to enable the clients to make a voluntary, informed and well-considered choice. The ultimate choice was respected.

The acceptors were given referral cards for use at the time of insertion. The PPIUCD acceptors who had vaginal deliveries received postplacental insertion (manual insertion immediately after delivery of the placenta). The PPIUCD acceptors who had cesarean deliveries received transcesarean insertion (manual insertion through the uterine incision of the abdominal delivery). These insertion techniques have been adequately described previously $[4,6]$ : those who preferred insertion at the end of puerperium (interval acceptors) were given a referral card to the Family Planning Outpatient Clinic of AUH. Refusers were referred to routine obstetrics and postpartum care. In all cases reasons for acceptance and refusals were recorded.

\section{Postpartum Counseling}

Counseling for postpartum family planning after vaginal delivery at AUH was offered to 1,661 women. Counseling was done after the client rested sufficiently, but before she was discharged from the hospital. Various professionals shared in the process of counseling.

The PPIUCD acceptors were prepared for predischarge insertion (instrumental insertion using Kelly placental forceps within $48 \mathrm{~h}$ after delivery). The interval IUCD acceptors were again given a referral card to the Family Planning Outpatient Clinic of AUH. Records were kept on the numbers of PPIUCD and interval IUCD acceptors. In addition, the actual numbers of IUCD insertions were recorded.

\section{Results}

Demographic characteristics of these women are given in table 1 . There was no difference in the age distribution between the subjects who were counseled antenatally or postpartum. Primigravidas formed a small percentage, while more than half of the subjects were grandmultipara having had 5 or more previous deliveries. Our clientele were mostly of lower socioeconomic status, and more than $45 \%$ of them had had no previous formal education. Moreover $40 \%$ of the subjects counseled had not used any contraceptives previously. Among those who had used contraceptives before, the IUCD was the most commonly used.

Of the 3,541 women counseled, 1,024 (28.9\%) accepted the use IUCD after delivery. Acceptance was approximately the same during antenatal and postpartum counseling: 26.4 and $31.8 \%$, respectively, as shown in table 2. Acceptance of the use of IUCD was higher among women with formal education than illiterate women as 


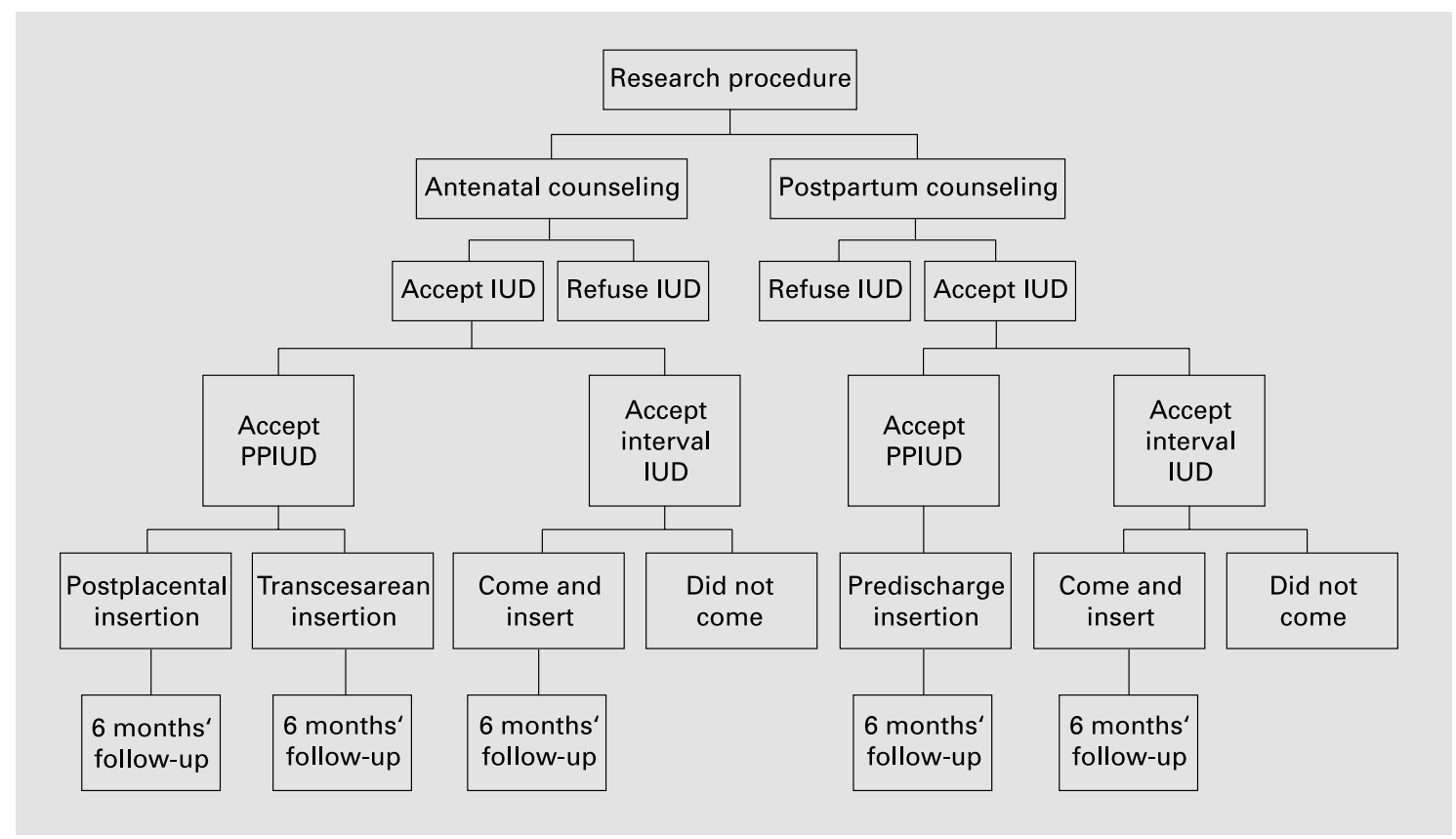

Fig. 1. Summary of the research procedure.

Table 1. Characteristics of subjects counseled for IUCD use

\begin{tabular}{|c|c|c|c|c|c|}
\hline \multirow[t]{2}{*}{ Characteristic } & \multicolumn{2}{|c|}{ Antenatal counseling } & \multicolumn{2}{|c|}{ Postpartum counseling } & \multirow[t]{2}{*}{ Total } \\
\hline & $\mathrm{n}$ & $\%$ & $\mathrm{n}$ & $\%$ & \\
\hline Total counseled & \multicolumn{2}{|l|}{1,880} & \multicolumn{2}{|l|}{1,661} & 3,541 \\
\hline \multicolumn{6}{|l|}{ Education } \\
\hline None & 870 & 46.3 & 756 & 45.5 & 1,626 \\
\hline Primary or more & 1,010 & 53.7 & 905 & 54.5 & 1,915 \\
\hline \multicolumn{6}{|c|}{ Previous use of contraceptives } \\
\hline IUCD & 934 & 49.6 & 724 & 43.6 & 1,658 \\
\hline None & 776 & 41.3 & 733 & 44.1 & 1,509 \\
\hline Other methods & 170 & 9.0 & 204 & 12.3 & 374 \\
\hline Age, years (mean \pm SD) & \multicolumn{2}{|c|}{$29.9 \pm 5.8$} & \multicolumn{2}{|c|}{$30.1 \pm 6.2$} & \\
\hline Parity (mean \pm SD) & \multicolumn{2}{|c|}{$4.2 \pm 1.4$} & \multicolumn{2}{|c|}{$4.1 \pm 1.5$} & \\
\hline
\end{tabular}

should be expected. Also as should be expected, women who had previously used contraceptive devices accepted the use of IUCD more than the women who had not (table 2). A small percentage of women with first pregnancy $(16 \%)$ as contrasted to one third of grandmultiparas accepted the use of IUCD. Most of the verbal acceptors counseled either antenatally (17.2\%) or postpartum (26.2\%) preferred interval IUCD to PPIUCD (table 3 ).

A total of 2,517 of the women counseled refused the use of IUCD after the indexed delivery as explained in table 4. Planning another pregnancy in the near future was relatively the most common reason followed by preference of interval IUCD and another method, namely lactational infertility. Complication from previous use of IUCD or absence of husbands were some of the other reasons. In the group counseled postpartum, $8 \%$ of the refusals were attributed to exhaustion or complications that occurred during or after labor. The decision to refuse was jointly made by the subject and her treating physician. About $11.4 \%$ of refusals made during antenatal counseling were based on inability to make the decision at that time. 
Table 2. Characteristics of verbal acceptors of IUCD use

Table 3. Verbal acceptance of IUCD and PPIUCD use

Table 4. Causes of verbal refusal of PPIUCD at the time of counseling

\begin{tabular}{|c|c|c|c|c|c|}
\hline \multirow[t]{2}{*}{ Characteristic } & \multicolumn{2}{|c|}{ Antenatal counseling } & \multicolumn{2}{|c|}{ Postpartum counseling } & \multirow[t]{2}{*}{ Total } \\
\hline & $\mathrm{n}$ & $\%$ & $\mathrm{n}$ & $\%$ & \\
\hline Acceptors & 496 & 26.4 & 528 & 31.8 & 1,024 \\
\hline Refusers & 1,384 & 73.6 & 1,133 & 68.2 & 2,517 \\
\hline Total counseled & 1,880 & & 1,661 & & 3,541 \\
\hline \multicolumn{6}{|l|}{ Education } \\
\hline None & 172 & 9.1 & 162 & 9.7 & 334 \\
\hline Primary school or more & 324 & 17.2 & 366 & 22.0 & 690 \\
\hline \multicolumn{6}{|l|}{ Previous use of contraceptives } \\
\hline IUCD & 262 & 13.9 & 242 & 14.5 & 504 \\
\hline None & 173 & 9.2 & 192 & 11.6 & 365 \\
\hline Other methods & 61 & 3.2 & 94 & 5.6 & 155 \\
\hline Age, years (mean $\pm \mathrm{SD})$ & \multicolumn{2}{|c|}{$32.6 \pm 6.0$} & \multicolumn{2}{|c|}{$33.0 \pm 6.0$} & \\
\hline Parity $($ mean \pm SD) & \multicolumn{2}{|c|}{$4.2 \pm 1.39$} & \multicolumn{2}{|c|}{$4.5 \pm 1.3$} & \\
\hline
\end{tabular}

\begin{tabular}{lrr}
\hline & \multicolumn{2}{l}{ Acceptance } \\
\cline { 2 - 3 } & $\mathrm{n}$ & $\%$ \\
\hline Antenatal counseling & & \\
Acceptors & & \\
$\quad$ PPIUCD & 172 & 9.2 \\
$\quad$ Interval IUCD & 324 & 17.2 \\
$\quad$ Subtotal & 496 & 26.4 \\
Refusers & 1,384 & 73.6 \\
Total & 1,880 & 100.0 \\
\hline Postpartum counseling & & \\
Acceptors $\quad$ PPIUCD & 92 & 5.5 \\
$\quad$ Interval IUCD & 436 & 26.2 \\
$\quad$ Subtotal & 528 & 31.7 \\
Refusers & 1,133 & 68.2 \\
\cline { 2 - 3 } Total & 1,661 & 99.9 \\
\hline
\end{tabular}

\begin{tabular}{|c|c|c|c|c|}
\hline & \multicolumn{2}{|c|}{ Antenatal counseling } & \multicolumn{2}{|c|}{ Postpartum counseling } \\
\hline & $\mathrm{n}$ & $\%$ & $\mathrm{n}$ & $\%$ \\
\hline Total counseled & 1,880 & & 1,661 & \\
\hline Total refusals & 1,384 & 73.6 & 1,133 & 60.3 \\
\hline $\begin{array}{l}\text { Planning another pregnancy in } \\
\text { near future }\end{array}$ & 511 & 36.9 & 352 & 31.1 \\
\hline Preference for interval IUCD & 324 & 23.4 & 436 & 38.4 \\
\hline Preference for another method & 184 & 13.3 & 50 & 4.4 \\
\hline Previous IUCD complication & 138 & 10 & 106 & 9.4 \\
\hline Husband absent & 69 & 5 & 24 & 2.1 \\
\hline Postpartum exhaustion or & & & & \\
\hline complication & - & - & 92 & 8.2 \\
\hline Intention to postpone the decision & 158 & 11.4 & 73 & 6.4 \\
\hline
\end{tabular}


Table 5. Verbal acceptance and actual insertion of IUCD

\begin{tabular}{lccc}
\hline & $\begin{array}{l}\text { Verbal } \\
\text { acceptance }\end{array}$ & $\begin{array}{l}\text { Actual } \\
\text { insertion* }\end{array}$ & $\begin{array}{l}\text { \% of actual } \\
\text { insertions }\end{array}$ \\
\hline Overall counseling & & & \\
$\quad$ PPIUCD & 264 & 188 & 71.2 \\
$\quad$ Interval IUCD & 760 & 55 & 7.2 \\
$\quad$ Overall total & 1,024 & 243 & 23.7 \\
\hline Antenatal counseling & & & \\
$\quad$ PPIUCD & 172 & 114 & 83.7 \\
$\quad$ Interval IUCD & 324 & 29 & 8.9 \\
$\quad$ Total & 496 & 143 & 28.8 \\
\hline Postpartum counseling & & & \\
$\quad$ PPIUCD & 92 & 74 & 80.4 \\
$\quad$ Interval IUCD & 436 & 34 & 7.8 \\
$\quad$ Total & 528 & 108 & 20.4 \\
\hline
\end{tabular}

$* \mathrm{p}<0.01$ acceptance and actual insertion.

Of the overall 1,024 verbal acceptors, only 243 (23.7\%) had the actual insertion (table 5). Of the 264 verbal acceptors for PPIUCD, 188 (71.2\%) had actual insertion while of 760 who preferred interval IUCD, only $55(7.2 \%)$ had actual insertion. The difference was statistically significant $(p=0.0001)$. Antenatal or postpartum counseling did not affect the actual insertion ( $p>0.05$; table 5).

Of the 243 women who had the IUCD fitted either as a PPIUCD or interval IUCD, 81 PPIUCD had special problems. Three had rheumatic heart diseases, 22 hypertensive toxemic pregnancy, and 5 chest diseases. Apart from the 21 women who had transcesarean IUCD insertion, 15 women had a cesarean section prior to the last (indexed) vaginal delivery. Fourteen women had a postplacental insertion of an IUCD before repair of an episiotomy or perennial tear. Seven women had a predischarge PPIUCD insertion in spite of a recently repaired episiotomy.

\section{Discussion}

In this study the women typically were of lower socioeconomic status and predominantly grandmultipara, parous women. About half of them were illiterate (table 1). The women were at increased obstetric risk on the event of any subsequent pregnancy. Therefore, this type of clientele required increased effort in emphasizing contraceptive use as prevention for future pregnancy that may help diminish maternal mortality and morbidity. Moreover, these women most likely belong to the crisisoriented group [1], which does not seek medical service until a problem has occurred.

The postpartum stay in the AUH after normal delivery is short (usually less than 1 day), due to the busy practice (about 12,000 deliveries per year) and the limited availability of beds. The short hospital stay might have limited the time available for considering predischarge insertion of the IUCD. Acceptance of the IUCD after indexed delivery was expressed by about $28.9 \%$ of the subjects counseled (table 3 ) for either PPIUCD or interval insertions. This figure represents less than what was expected, considering they had been given adequate family planning counseling and that about $45 \%$ of the subjects had previously used the IUCD for family planning. The reason for this suboptimal acceptance of IUCD insertion is not fully clear. A plausible explanation is the 'newness' of IUCD in the community. Much more importantly, this type of clientele tends to rely on the contraceptive effect of lactation for some time after childbirth (LAM), which is perceived as safe, free of charge and does not interfere with coitus. Furthermore, Egyptian women breast-feed for a long time (usually 2 years), as previously reported $[7,8]$.

Although LAM is safe and free of charge, it has two main disadvantages: (a) LAM reliability could expire at any time or at a time when it is not suitable for the woman to visit a clinic for initiation of another contraceptive method, and (b) given the high incidence of infant child morbidity particularly from gastrointestinal diseases, and the need to reduce breast-feeding during the infant's illness, reliance on LAM could become ineffective, thereby leaving the woman vulnerable to conception. Therefore LAM must be viewed as a double-edged sword. Enthusiasm for LAM as a reliable method should be guarded by its limitations, and therefore clients, particularly crisisoriented ones, should be encouraged to use a long-term contraceptive method such as IUCD insertion shortly after childbirth. The lower-than-expected acceptance of using the IUCD could also be due to the desire to have another pregnancy shortly after the current one (table 4), reflecting a preference for a big family in rural Upper Egypt. The status of the counselors, whether medical personnel or HIN graduate, did not have any effect one the lower-than-expected rate of acceptance.

The time of the counseling also, whether during antenatal or postnatal visit, did not make a difference in the rate of acceptance except in women in the age-group 4044 years where the acceptance rate was higher during 
postnatal counseling $(p<0.05)$. The difference might have been due to the increased labor complication rate associated with higher parity.

Since the 1970s, most researchers have focused on the performance rather than the factors that affect acceptance of PPIUCD. In 1975 the International Postpartum Family Planning Program reported an acceptance rate of 12 $25 \%$ [9] similar to our finding (28.9\%). It is hoped that continuation of effort in promoting acceptance of PPIUCD will serve to 'convince the community' of its feasibility, safety and other special merits.

Actual IUCD insertion rates were much lower than verbal acceptance rates, by an overall factor of 4.2. It was even worse with the interval IUCD by a factor of 13.8 . Probable explanations would be that (a) some of the women had IUCD inserted at other medical services; (b) some of them might have forgotten all about contraception; (c) some were overwhelmed by other obligations in the household that included childcare, or (d) some believed in the contraceptive effect of lactation. It is noteworthy to point out that there were more actual insertions with PPIUCD than interval IUCD, thereby indicating the superiority of PPIUD over interval IUCD.

\section{Conclusion}

Verbal acceptance of IUCD was less than expected and actual insertion was even worse. For these women, the only opportunity to receive information about contraceptive devices is during childbirth when they are in contact with medical personnel. Hence, it is suggested that family planning should be integrated with maternal and childcare services in order to effectively promote the use of contraceptive devices in women who otherwise and on their own initiative would not seek the use of such protective devices.

\section{Acknowledgment}

The authors would like to thank all the staff including physicians, nurses and nonmedical personnel of the Department of Obstetrics and Gynecology, Assiut University Hospital, Assiut Egypt, the clients who participated in this study and the staff of the Association of Voluntary Safe Contraception.

\section{References}

1 Darnel L, Jones MD, David R, Helbert MD: Postpartum contraception. Clin Med 1975;82: 20-22.

2 Xu JX, Reusche C, Burdan A: Immediate postplacental insertion of intrauterine device: A review of Chinese and world experiences. Adv Contracept 1994;10:71-82.

3 Gomesz-Rogers C, Ibarra-Polo AA, Faundes A, Guiloff E: Effect of IUCD and another contraceptive methods on lactation. Proc 8th Int Conf Int Planned Parenthood Fed, Santiago, April 1967, pp 328-334.
4 Chi IC, Farr G: Postpartum IUCD contraception: A review of international experience. Adv Contracept 1989;5:127-146.

5 Tatum HJ, Beltran RS, Ramos R, Van Kets H, Sivin I, Schmidt FH: Immediate postplacental insertion of GYNE-T 380 and GYNE-T 380 postpartum intrauterine contraceptive devices: Randomized study. Am J Obstet Gynecol 1996;175:1231-1235.

6 Cordero CF, Grinvn S, Henr JT, Herper PB, Gulhane TG, Tweedy S, Kurica A: AVSC Postpartum IUCD Curriculum Trainer's Guide. New York, AVSC International, 1997, pp 211.
7 Shaaban MM, Kennedy KI, Sayed GH, Ghaneimah SA, Abdel-Allem AM: The recovery of fertility during breast-feeding in Assiut, Egypt. J Biosoc Sci 1990;22:19-32.

8 Kamel MA: Study on the Impact of Improved Breast-Feeding Practice on Lactational Performance and Reproductive Health; MD thesis Department of Obstetric and Gynecology, Faculty of Medicine Assiut University, 1992.

9 Castadot RG, Sivin I, Reyes P, Alers JO, Chapple M, Russel J: The International Postpartum Family Planning Program: Eight years of experience. Rep Popul Fam Plann 1975;18:1-53. 